\title{
CORE, MANTLE, CRUST, CRUST, MANTLE, CORE
}

In the mirror I'm giving a lecture on geology, but when I touch my mouth, there's just some clay beads standing in for teeth. I think, Yeah, I ate the stamp with the wildflowers, but this is a whole passageway I was hoping to ditch. Dan and Julie are in the next room making out, so I splash some root beer on my face and continue preaching science. This time I'm on in Spanish, and I'm laughing a little, 'cause it's not the talking I took in school. I'm pretty good, I think, and I'm wondering if somehow there's a videotape of all this I might watch later. There's always that rocky part in the afternoons that gets me real lonely, and this is just the thing to shepherd me back up top. Another minute goes by, or an hour or four, and I'm making lists of the ways wincing is spelled. I can think of seven when the door opens, and it's Julie, who's ready to go, and she's hugging the doorframe loose, with no connection, but I'm so close to the tiles that I have trouble not kissing each one goodbye. 